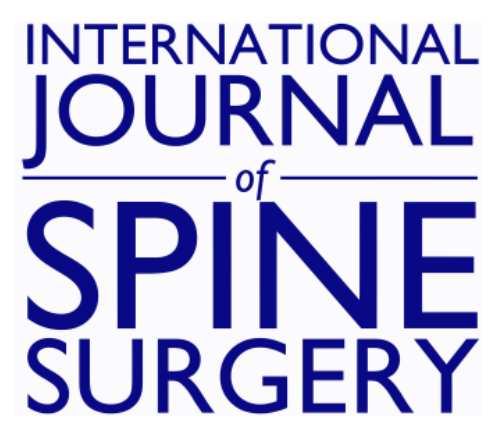

\title{
Surgeons' Learning Curve of Renaissance Robotic Surgical System
}

\author{
HENRIK C. BÄCKER, CHRISTINA E. FREIBOTT, CARSTEN PERKA and MARK \\ WEIDENBAUM
}

Int J Spine Surg 2020, 14 (5) 818-823

doi: https://doi.org/10.14444/7116

http://ijssurgery.com/content/14/5/818

This information is current as of April 26, 2023.

Email Alerts Receive free email-alerts when new articles cite this article. Sign up at: http://ijssurgery.com/alerts 


\title{
Surgeons' Learning Curve of Renaissance Robotic Surgical System
}

\author{
HENRIK C. BÄCKER, MD, ${ }^{1,2}$ CHRISTINA E. FREIBOTT, BA, ${ }^{1}$ CARSTEN PERKA, MD, ${ }^{2}$ MARK \\ WEIDENBAUM, MD ${ }^{1}$ \\ ${ }^{I}$ Department of Orthopaedic Surgery, Columbia University Medical Center-Presbyterian Hospital, The Spine Hospital at New York Presbyterian, New York, \\ New York, ${ }^{2}$ Center for Muskuloskeletal Surgery, Charité Berlin, University Hospital Berlin, Berlin, Germany
}

\begin{abstract}
Introduction: A few articles on robot-assisted pedicle screw placement described the learning curve but failed to report on the overall operative time, including cases in which the robotic system malfunctioned. The purpose of this study was to identify a single surgeon's learning curve including estimated blood loss, surgery time, anesthesia time, robot time, and complications.

Methods: A retrospective study was performed between January 2016 and August 2018 for patients who underwent posterior spinal fusion using the Mazor robot. Based on the charts, the robot time, time of anesthesia, and surgery time were recorded, as were the complications, misplacement of screws, and blood loss.

Results: Of 62 robot-assisted surgeries scheduled, only 46 were performed $(74.2 \%)$ upon patients with a mean age of $63.3 \pm 13.0$ years. The mean follow-up time was $13.2 \pm 8.0$ months and most commonly a fusion from L4 to S1 was performed (20/46, 43.5\%). A high improvement in estimated intraoperative blood loss was observed of $755.7 \pm 344.7$ $\mathrm{mL}$ (slope $=-9.89$ ). A decrease in time in anesthesia, surgery, and robotic usage was identified with a slope factor of $-3.64\left(R^{2}=.22, \mathrm{SE}=85.4, P<.005\right),-3.97\left(R^{2}=0.30, \mathrm{SE} 75.8, P<.005\right),-0.69\left(R^{2}=.07, \mathrm{SE}=27.8, P<.09\right)$, respectively. Furthermore, a decrease in pedicle screw insertion time and operative time was found (slope $=-0.05, R^{2}=$ $.02, \mathrm{SE}=3.4, P=.37$ ). In total, 5 major complications (cases $8,19,21,35,43)$ and 6 minor complications (cases $4,14,15$, $20,29)$, were identified $(21.7 \%)$ without any learning curve.

Conclusions: Robot pedicle screw insertion shows no major learning curve; however, the blood loss and the installation process of the system improved with experience.
\end{abstract}

Level of Evidence: 3.

New Technology

Keywords: robotic, Mazor, degenerative, spinal stenosis, pedicle screw, outcome, learning curve, complication

\section{INTRODUCTION}

There were approximately 3.6 million spine surgery cases in the United States between 2001 and 2010, with increasing prevalence each year. ${ }^{1}$ In spine fusion surgeries, one of the most common complications is pedicle screw misplacement, which may cause injury to the spinal cord or nerve roots. Screw misplacement can occur up to $8.7 \%$ of the time and can lead to clinically relevant symptoms in $0.2 \%$ to $21 \%$ of the cases. ${ }^{2-5}$

Robot-assisted surgery was first introduced in 1988, and its application was further used in spine surgery in 2003 as a means to decrease iatrogenic surgical complications. ${ }^{6}$ The theory of robot-assisted spine surgery is based on decreased complications and improved pedicle screw insertion accuracy. ${ }^{7,8}$ For perfect accuracy of pedicle screw placement, results in the literature vary for freehand placement between $35.5 \%$ and $95.0 \%$ and for robotassisted placement between $38.4 \%$ and $98.6 \%{ }^{9-15}$ In addition, the decrease in disc height at the proximal adjacent segment was significantly less in the robot group compared with freehand posterior spinal fusion, a finding related to less manipulation and injuries to the proximal facet joints. ${ }^{16}$

Although robot-assisted spine surgery can, in theory, provide an efficient and accurate mode of hardware placement, the technology is relatively new and still seldom used among spine surgeons. As with any new surgical technology, there is a significant learning curve involved with the robotic system. Urakov et al ${ }^{17}$ described improved efficiency with increased case load, but they also noted that the learning curve was largely dependent on the experience and the dedication of the operator. Khan 
et al, ${ }^{18}$ however, described a minimal learning curve involved with robotic spine surgery and stated the efficacy of the technique. Most of the literature describing the learning curve using robotic surgery focused on pedicle screw insertion time but failed to report on the overall operative time, including cases in which the robotic system malfunctioned. Therefore, the purpose of this study was to investigate our senior surgeon's (M.W.) learning curve for the Renaissance Robotic Surgical System (Mazor Robotics Ltd., Caesarea, Israel) based on general complications, required revision surgeries, operative time, anesthesia time, robotic usage time, and estimated blood loss.

\section{METHODS}

Between January 2016 and August 2018, a total of 62 consecutive cases were scheduled to use the Renaissance Robotic Surgical System (Mazor) by the senior author (M.W.). Of the 62 cases, 16 patients were excluded owing to robotic hardware failure secondary to difficult installation and registration failure. All cases were elective spine fusion surgery for degenerative spondylolisthesis, scoliosis, and disc disease. The decision for using the robotassisted versus conventional posterior instrumentation was made on the basis of clinical findings independent of this study. All patients suffered from spinal stenosis due to spondylolisthesis, kyphosis, or scoliosis that required reduction and dorsal spondylodesis.

A retrospective chart review was performed and data were collected to determine the demographics, follow-up time, comorbidities, operative time, anesthesia time, robotic usage time, postoperative complications, intraoperative screw misplacement, and estimated blood loss.

The surgery time was defined as the period between the first incision and closure. The robotic time, which was recorded by the robotic system, was defined as the pedicle screw insertion time. For the postoperative protocol, external bone growth stimulator usage was recorded. In addition, postoperative complications and revision surgery were noted. The robotic system hardware failure rate secondary to difficult installation and registration issues were also recorded.

For statistical analysis, we calculated the line of best fit and presented the slope factor, $R^{2}, \mathrm{SE}$, and $F$ value. The slope factor of the trend line was calculated because it represents an array of the straight line that best fits on the data. The $R^{2}$ described the coefficient of multiple determination for multiple regression with the SE and the correlating significance.

In total, the robotic system was requested in 62 cases; however, due to technical issues such as registration in 1 patient, installation in 13 cases, a software bug in 1 patient, and placement in another patient, it could not be used in 16 patients $(25.8 \%)$. Those cases were equally distributed among the cohort (cases 4, 5, 22, 23 30, 32, 34, 35, 38, 40, 42, $44,48,53,57$, and 62, the last case). All the difficulties were observed in the operating room without any learning curve. This left 46 patients $(72.2 \%, \mathrm{n}=46 / 62)$ who met inclusion criteria and thus robotic pedicle screw placement was performed on them. Operative time was not recorded in 3 cases. Robotic time was not recorded in 7 cases.

All calculations and graphs were performed with Microsoft Excel 2019 and IBM SPSS Statistics, Version 25 (Armonk, NY). The institutional review board approved the study. For statistics, we performed a linear regression model, which provides correlation between the 46 cases included and surgery time; thereby, the data points are connected by the best fit line that can be reasonably approximated. For testing the sample for normal distribution, the Shapiro-Wilk test was applied. A multivariate analysis of variance $t$ test as well as post hoc least significant difference test for descriptive statistics and calculation of significances were used. The level of significances were set to $* P$ value $\leq .05 ; * * P$ value $\leq 0.01$; and $* * * P$ value $\leq 0.005$ Mean and standard deviation are presented.

\section{RESULTS}

In our cohort, the mean age of patients was 63.3 \pm 13.0 years (range, 28.5 to 83.0 years) and a majority $(67.4 \% ; 31 / 46)$ of the patients were women. The mean follow-up time was $13.2 \pm 8.0$ months (range, 1.2 to 26.4 months). The median height was $157.5 \mathrm{~cm}$ (range, 150.0 to $195.0 \mathrm{~cm}$ ) and weight was $86 \mathrm{~kg}$ (range, 49.5 to $187.5 \mathrm{~kg}$ ). Subsequently, the body mass index was $31.4 \mathrm{~kg} / \mathrm{m}^{2}$ (range, 20.0 to $83.3 \mathrm{~kg} / \mathrm{m}^{2}$ ).

A total of 27 patients $(67.4 \%)$ received primary spine surgery, whereas 15 patients $(32.6 \%)$ underwent revision spine surgery. Also, 26 patients $(56.5 \%)$ had comorbidities ranging from cancer (n $=12)$, diabetes $(n=5)$, rheumatoid arthritis $(n=2)$, and other immunosuppressive disorders $(\mathrm{n}=3)$. In 

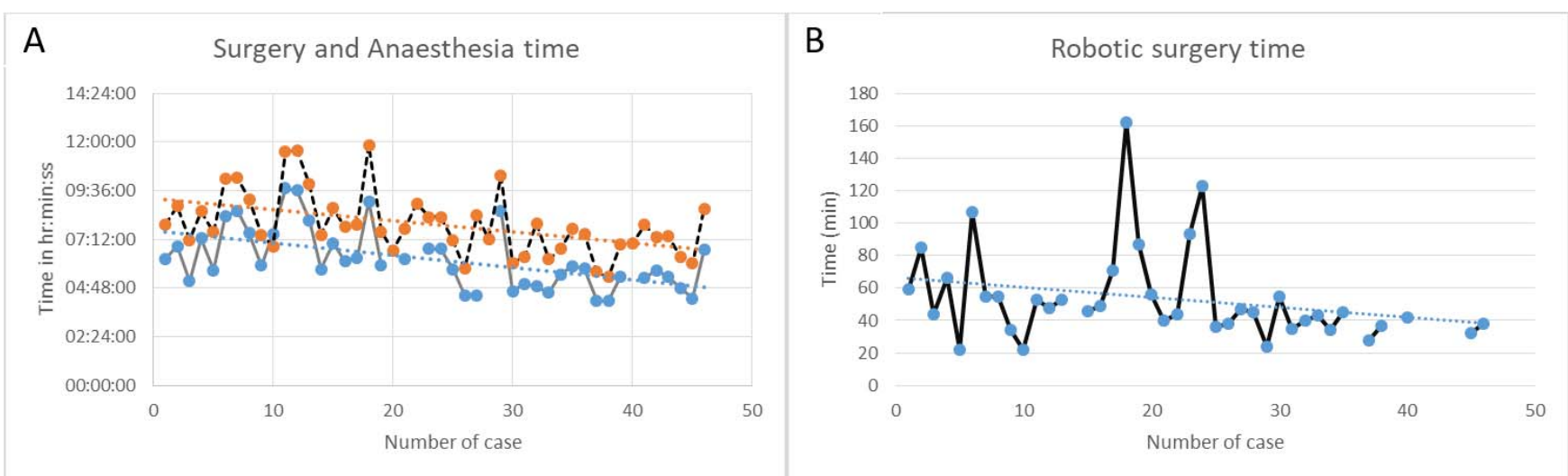

Figure 1. Individual times and the corresponding trend line for (A) surgery and anesthesia time. (B) Robotic surgery time.

an additional 4 patients, history of hepatitis, gout, or earlier methicillin-resistant Staphylococcus aureus infection were reported. Furthermore, 5 patients reported current or former smoking status.

Indications included spondylolisthesis (16/46), scoliosis $(9 / 46)$, combined spondylolisthesis and scoliosis (4/46), severe degenerative disc arthritis (14/46), kyphosis $(2 / 46)$, and displaced interbody spacer $(1 / 46)$. In addition, a facet hypertrophy and sacroiliac joint arthritis were identified in 1 patient each, and 3 severe facet arthropathies as well as spinal stenosis was diagnosed in 43 cases. Two patients had significant motor deficits leading to foot drop. The most common robotic surgery performed was fusion from L4 to S1 $(n=20)$, followed by interbody fusions $(\mathrm{n}=11), \mathrm{L} 3$ to $\mathrm{S} 1$ fusion $(\mathrm{n}=5), \mathrm{L} 5$ to $\mathrm{S} 1$ fusion $(\mathrm{n}=3), \mathrm{L} 1$ to $\mathrm{S} 1$ fusion $(n=2)$, L4 to ilium fusion $(n=2)$, L3 to ilium fusion $(\mathrm{n}=1)$, T10 fusion $(\mathrm{n}=1)$, and T12 to pelvis posterior spinal fusion $(n=1)$. A mean of $4.5 \pm 3.2$ levels were fused using, on average, $6.7 \pm 2.9$ pedicle screws. In total, 281 screws were placed and the overall operative time was $373.6 \pm 88.7$ minutes with a mean anesthesia time of $477.6 \pm 94.6$

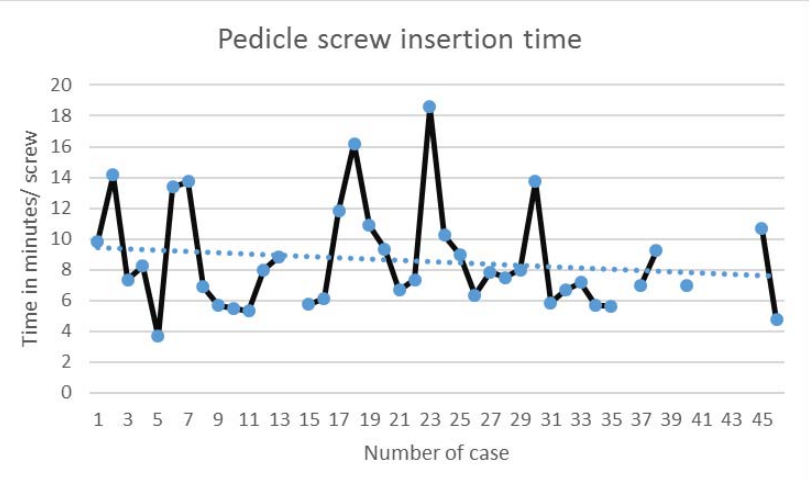

Figure 2. Pedicle screw insertion time over time. minutes. The pure Renaissance robotic surgical system usage was $53.7 \pm 28.1$ minutes, ranging from 22 to 162 minutes. A decrease in time in anesthesia, surgery, and robotic usage was identified with a slope factor of $-3.64\left(R^{2}=.22, \mathrm{SE}=85.4, P\right.$ $<.005),-3.97\left(R^{2}=.30, \mathrm{SE}=75.8, P<.005\right)$, and $-0.69\left(R^{2}=.07, \mathrm{SE}=27.8, P=.094\right)$, respectively. The individual times and the corresponding trend line are illustrated in Figure $1 \mathrm{~A}$ and 1B. The insertion time per pedicle screw was 8.6 minutes ( \pm 3.3 minutes) with a decreasing trend in operative time (slope $=-0.05, R^{2}=.02, \mathrm{SE}=3.4, P=.37$ ) as shown in Figure 2.

The estimated blood loss was $755.7 \pm 344.7 \mathrm{~mL}$, which showed a downward trend over the time period (slope factor $=-9.89, R^{2}=.15, \mathrm{SE}=325.8, P$ $=.009$; Figure 3 ). For time per level a decreasing trend was observed however, without any significances. All values are illustrated in Table 1.

The overall complication rate was $21.7 \%(n=10 /$ 46). Of the 10 complications, 5 were major complications $(10.9 \%)$ that required revision surgery. Those were seen in case numbers $8,19,21,35$, and 43 and included 2 deep wound infection and

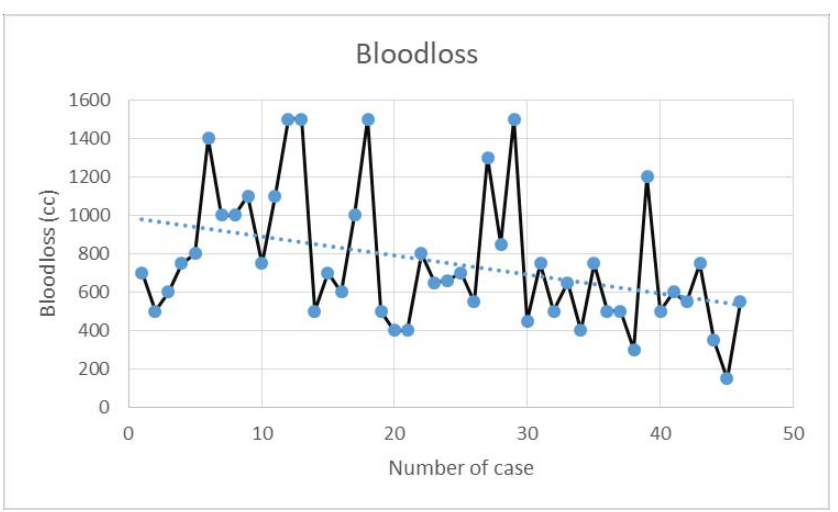

Figure 3. Bloodless over time. 
Bäcker et al.

Table 1. Operating time and estimated blood loss using the robot assisted pedicle screw insertion.

\begin{tabular}{|c|c|c|c|c|c|c|c|c|c|c|}
\hline & Overall & Slope & $R^{2}$ & SE & $P$ Value & Per level & Slope & $R^{2}$ & SE & $P$ Value \\
\hline Anesthesia time & $477.6 \pm 94.6 \mathrm{~min}$ & -3.64 & .22 & 85.4 & $<.005$ & $161.3 \pm 46.1 \mathrm{~min}$ & -0.54 & .02 & 11.7 & .404 \\
\hline Surgery time & $373.6 \pm 88.7 \mathrm{~min}$ & -3.97 & .30 & 75.8 & $<.005$ & $126.7 \pm 43.0 \mathrm{~min}$ & -0.85 & .05 & 11.5 & .158 \\
\hline Robot time & $53.7 \pm 28.1 \mathrm{~min}$ & -0.69 & .07 & 27.8 & .094 & $16.6 \pm 6.4 \mathrm{~min}$ & -0.15 & .06 & 10.6 & .145 \\
\hline Pedicle screw time & $8.6 \pm 3.3 \mathrm{~min}$ & -0.05 & .02 & 3.4 & .37 & & & & & \\
\hline Blood loss & $755.7 \pm 344.7 \mathrm{~mL}$ & -9.89 & .15 & 325.8 & .009 & $258.7 \pm 139.9 \mathrm{~mL} \mathrm{cc}$ & -2.23 & .04 & 12.7 & .187 \\
\hline
\end{tabular}

Bold indicates statistical significance.

fascia dehiscence, 2 acute postoperative epidural bleedings with left leg and foot neurological deficits, and 1 neurological impairment not related to a postoperative hematoma. Three of these patients with postoperative complications had a medical history of hepatitis, cancer, or immunosuppressive disease. There were 6 minor complications (cases 4 , 14, 15, 20, and 29). These consisted of postoperative fever in 2 cases treated with antibiotics, 1 asymptomatic stress fracture, 1 complex regional pain syndrome of the right leg, and 1 postoperative adjacent segment stenosis. Two of the patients with minor complications had diabetes, 1 had rheumatoid arthritis, and 1 had hepatitis with a previous smoking history.

In 4 patients, 9 screws were placed inaccurately $(9 / 281,3.2 \%)$; these were identified and revised intraoperatively (case numbers 19, 24, 36, and 37). No learning curve was identified for complications and misplacement of screws. For postoperative follow-up, computed tomography was not performed routinely but only in patients who presented with complications. None of the neurological complaints were related to malposition of pedicle screw placement.

\section{DISCUSSION}

In our cohort of 46 patients, 281 pedicle screws were placed with only 9 malpositioned screws $(3.2 \%)$. The robotic time showed only minor improvement over experience in terms of trend line slope $(-0.69)$, whereas significant slopes were identified for anesthesia $(-3.97, P<.005)$ and surgery times $(-3.64, P<.005)$. Furthermore, a statistically significant improvement in estimated intraoperative bleeding was identified with a slope of $-9.89(P=.009)$. For surgery, anesthesia, and robot times as well as blood loss per level, a decreasing slope was found without any significances. No real learning curve was observed for the 5 minor and 5 major complications. No direct robotic complications such as implant failure or placement of the pedicle screws, including screw related neurological deficits, were recorded. However, 2 patients with postoperative hematoma presented with neurological symptoms.

The perfect accuracy in freehand pedicle screw placement is between $35.5 \%$ and $95.0 \%$ and for robot-assisted screw placement between $38.4 \%$ and $98.6 \%$, as reported in the literature. ${ }^{9,11-14}$ Even though there are studies addressing the learning curve for using the robotic spine surgery system, these only included pedicle screw insertion time and complication rate over time. Other factors such as estimated blood loss, installation time, and actual usage rate were not described in the past.

The learning curve, safety, and feasibility was investigated by Khan et al. ${ }^{18}$ The authors reported no screw misplacement and no complications within the first 20 patients using the robotic spine surgery system. The mean time for screw insertion was 3.6 minutes, and the authors ${ }^{18}$ concluded that only a minimal learning curve exists.

In a study conducted by Urakov et al, ${ }^{17}$ a total of 306 pedicle screws inserted using the robotic spine surgery system were investigated by surgeons with different levels of experience. They could not find any statistically significant differences when analyzing years of experience in the robot operators. When looking for comparison to fluoroscopy-guided conventional pedicle screw insertion in metastatic disease in thoracolumbar spine, the misplacement rate was rather high, with $15.6 \%$ in the robotic group and $16.4 \%$ in the conventional group, although the robotic group was more accurate. The mean surgery time was slightly shorter with 226.1 minutes compared with 264.1 minutes, without any significance; however, the radiation time was significantly higher in the robot group. Furthermore, no significance in complications was described, which occurred in $14.3 \%$ of the robot group and $22.9 \%$ of the conventional group. ${ }^{9,19}$ As all studies concluded, the robot assisted pedicle screw placement is a safe and effective technique and is also cost-effective. ${ }^{20-22}$ 
In our cohort, the robot-assisted spine surgery was scheduled in 62 cases; however, only in 46 patients $(74.2 \%)$ was it used due to system setup failure. This was caused due to registration in 1 patient, installation process in 13 cases, software bug in 1 case or placement in another patient. All issues took place in the operating room, leading to abortion of the robot use. However, no correlation among cases and learning curve was identified. This demonstrates that in addition to the surgeons' learning curve, the team itself (including scrub nurses, company representatives, residents and surgeons) need to be trained more effectively in order to improve the "failure" rate. This includes the scrub nurses and residents, especially for the installation process such as the mounting of the device over the operating room table. Secure placement is obligatory to facilitate a safe application and avoid the device falling on patients, as described in the literature. In addition, the device should be checked prior to usage and frequently serviced to avoid any unexpected software bugs. Finally, the residents need to know how to place and tap the guide into the bone because this may slightly shift the starting point. This can be prevented by visualizing the tip of the guide as it anchors in the pedicle.

In total, 281 screws were placed in the pedicles and a mean of $4.5 \pm 3.2$ levels (range, 1 to 6 ) were fused; however, in the literature and according to Medtronic the number of levels depends upon the intraoperative radiography. ${ }^{23}$ The average time was 8.6 minutes $( \pm 3.3$ minutes $)$ per screw placement, with a negative trend in surgery time (slope $=-0.05$ ). Similar results were found for the robotic time, in addition to surgery and anesthesia times, which demonstrated the highest trend with a slope of -3.64 and -3.97 , respectively. In addition, we found an even higher slope $(-9.89)$ for the intraoperative bleeding trend. The complications and misplacement of pedicle screws did not follow any patterns among the level of experience. When looking for anesthesia time, surgery time, and robot time per level, a negative trend was identified without any significances. This is likely related to the installation time of the robot, which may be relative to the actual operating time.

Our data suggest that the learning curve for pedicle screw placement in terms of time and complication rate is minimal for an experienced surgeon. However, when looking at anesthesia time, surgery time, and blood loss, a statistically significant correlation was observed. This suggests that the major improvement in time is related to the learning curve of the operating team including, but not limited to, surgeons, nurses, those tasked with surgical positioning, and company representatives for optimizing the timing of installation of the robotic system.

It is important to note that this study investigated an experienced single surgeon's learning curve using a retrospective study design and the decision on robot-assisted versus conventional screw placement was based on clinical findings. The assisting staff including residents, scrub nurses, and company representatives varied over time, which may have influenced the operative time as well as the installation process somewhat. In a few cases, no data on screw insertion time and surgery time were found. In terms of the preoperative robot time, it has to be mentioned that if there was any issue with mounting of the device, hardware, or software, the surgeon decided to convert to conventional screw placement to avoid any delay. Furthermore, although different indications existed for surgery, no significant correlation between individual procedures were identified except for the displaced intervertebral body, which took 9 minutes 36 seconds. Regarding the estimated blood loss that was recorded, this correlated slightly by the procedure performed and surgery time however, among our cohort it was equally distributed. Finally, a computed tomography scan is not performed routinely in a follow-up evaluation. The positions of the screws were evaluated intraoperatively, and misplacements that required changes were mentioned in the charts and found on the intraoperative fluoroscopy scan.

\section{CONCLUSIONS}

This study addresses a single surgeon's learning curve of a robot-assisted pedicle screw placement using the Mazor robot. For the actual placement of the screws and complication rate, no learning curve was identified. However, we observed a significant correlation between the surgeon's experience and the anesthesia time, intraoperative surgical time, and blood loss. This is most likely related to the logistics of installation and positioning of the robot as well as an improvement in teamwork.

\section{REFERENCES}

1. Goz V, Weinreb JH, McCarthy I, Schwab F, Lafage V, Errico TJ. Perioperative complications and mortality after 
spinal fusions: analysis of trends and risk factors. Spine (Phila Pa 1976). 2013;38(22):1970-1976.

2. Molliqaj G, Schatlo B, Alaid A, et al. Accuracy of robotguided versus freehand fluoroscopy-assisted pedicle screw insertion in thoracolumbar spinal surgery. Neurosurg Focus. 2017;42(5):E14.

3. Kosmopoulos V, Schizas C. Pedicle screw placement accuracy: a meta-analysis. Spine (Phila Pa 1976). 2007;32(3):E111-E120.

4. Lonstein JE, Denis F, Perra JH, Pinto MR, Smith MD, Winter RB. Complications associated with pedicle screws. $J$ Bone Joint Surg Am. 1999;81(11):1519-1528.

5. McAfee PC, Cassidy JR, Davis RF, North RB, Ducker TB. Fusion of the occiput to the upper cervical spine. A review of 37 cases. Spine (Phila Pa 1976). 1991;16(suppl 10):S490S494.

6. Kwoh YS, Hou J, Jonckheere EA, Hayati S. A robot with improved absolute positioning accuracy for CT guided stereotactic brain surgery. IEEE Trans Biomed Eng. 1988;35(2):153160.

7. Shoham M, Burman M, Zehavi E, Joskowicz L, Batkilin E, Kunicher Y. Bone-mounted miniature robot for surgical procedures: concept and clinical applications. IEEE Trans Robot Automat. 2003;19(5):893-901.

8. Shoham M, Lieberman IH, Benzel EC, et al. Robotic assisted spinal surgery-from concept to clinical practice. Comput Aided Surg. 2007;12(2):105-115.

9. Fan Y, Du JP, Liu JJ, et al. Accuracy of pedicle screw placement comparing robot-assisted technology and the freehand with fluoroscopy-guided method in spine surgery: an updated meta-analysis. Medicine (Baltimore). 2018;97(22):e10970.

10. Pechlivanis I, Kiriyanthan G, Engelhardt M, et al. Percutaneous placement of pedicle screws in the lumbar spine using a bone mounted miniature robotic system: first experiences and accuracy of screw placement. Spine (Phila Pa 1976). 2009;34(4):392-398.

11. Keric N, Eum DJ, Afghanyar F, et al. Evaluation of surgical strategy of conventional vs. percutaneous robotassisted spinal trans-pedicular instrumentation in spondylodiscitis. J Robot Surg. 2017;11(1):17-25.

12. Lieberman IH, Hardenbrook MA, Wang JC, Guyer RD. Assessment of pedicle screw placement accuracy, procedure time, and radiation exposure using a miniature robotic guidance system. J Spinal Disord Tech. 2012;25(5):241-248.

13. Ringel F, Stuer C, Reinke A, et al. Accuracy of robotassisted placement of lumbar and sacral pedicle screws: a prospective randomized comparison to conventional freehand screw implantation. Spine (Phila Pa 1976). 2012;37(8):E496E501.

14. Hyun SJ, Kim KJ, Jahng TA, Kim HJ. Minimally invasive robotic versus open fluoroscopic-guided spinal instrumented fusions: a randomized controlled trial. Spine (Phila Pa 1976). 2017;42(6):353-358.

15. Gaines RW Jr. The use of pedicle-screw internal fixation for the operative treatment of spinal disorders. $J$ Bone Joint Surg Am. 2000;82-A(10):1458-1476.

16. Kim HJ, Kang KT, Chun HJ, et al. Comparative study of 1-year clinical and radiological outcomes using robotassisted pedicle screw fixation and freehand technique in posterior lumbar interbody fusion: a prospective, randomized controlled trial. Int J Med Robot. 2018;14(4):e1917.

17. Urakov TM, Chang KH, Burks SS, Wang MY. Initial academic experience and learning curve with robotic spine instrumentation. Neurosurg Focus. 2017;42(5):E4.

18. Khan A, Meyers JE, Siasios I, Pollina J. Next-generation robotic spine surgery: first report on feasibility, safety, and learning curve. Oper Neurosurg (Hagerstown). 2019;17(1):6169

19. Solomiichuk V, Fleischhammer J, Molliqaj G, et al. Robotic versus fluoroscopy-guided pedicle screw insertion for metastatic spinal disease: a matched-cohort comparison. Neurosurg Focus. 2017;42(5):E13.

20. Fiani B, Quadri SA, Farooqui M, et al. Impact of robotassisted spine surgery on health care quality and neurosurgical economics: a systemic review. Neurosurg Rev. 2020;43(1):17-25.

21. Shaw KA, Murphy JS, Devito DP. Accuracy of robotassisted pedicle screw insertion in adolescent idiopathic scoliosis: is triggered electromyographic pedicle screw stimulation necessary? J Spine Surg. 2018;4(2):187-194.

22. Chenin L, Capel C, Fichten A, Peltier J, Lefranc M. Evaluation of screw placement accuracy in circumferential lumbar arthrodesis using robotic assistance and intraoperative flat-panel computed tomography. World Neurosurg. 2017; 105:86-94.

23. Staub BN, Sadrameli SS. The use of robotics in minimally invasive spine surgery. J Spine Surg. 2019;5(suppl 1):S31-S40.

Disclosures and COI: The authors have received no funding for this study and report no conflicts of interest.

Corresponding Author: Henrik C. Bäcker, MD, Spine, Department of Orthopaedic Surgery, Columbia University Medical Center/New York Presbyterian Hospital, 622 West 168th St PH-11, New York, NY 10032. Phone: (212) 305-3912; Fax: (212) 342-1749; Email: Henrik.baecker@ sports-med.org.

Published 11 November 2020

This manuscript is generously published free of charge by ISASS, the International Society for the Advancement of Spine Surgery. Copyright (c) 2020 ISASS. To see more or order reprints or permissions, see http://ijssurgery.com. 